\title{
Canada leads charge to allow industry to fortify foods
}

Previously published at www.cmaj.ca

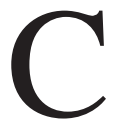

anada is leading an international charge to amend world food standards to allow industry more discretion in the fortification of foods through the addition of vitamins and minerals.

Although critics say that the rationale for such a change hasn't been established and that it could lead to excessive consumer exposure to some nutrients, Health Canada argues such discretionary fortification is justified by consumer interest and demand.

At issue is whether to give food manufacturers the green light to add vitamins and minerals to food at their discretion within the parameters of food standards and guidelines established by the Codex Alimentarius Commission.

The commission, created in 1963 by the Food and Agriculture Organization of the United Nations and the World Health Organization, maintains the Codex, a set of standards that essentially serves as the globe's nutritional frame of reference and code of practice.

Existing Codex principles regarding fortification of food require that manufacturers demonstrate a public health need before adding vitamins and minerals to products. But in November 2008, a working group led by Health Canada's delegation to the commission proposed that Codex principles be amended to allow for fortification with "no specific nutritional rationale such as a public health or special dietary purpose or the improvement of the nutritional quality of foods and diets."

If approved, the amendment would open the door for food manufacturers to adopt discretionary fortification with the commission's imprimatur. Health Canada proposed that the amendments go into effect in 2015.

Health Canada's rationale for championing discretionary fortification and amending the Codex is multifaceted, spokesman David Thoms wrote in an email. Several jurisdictions, including

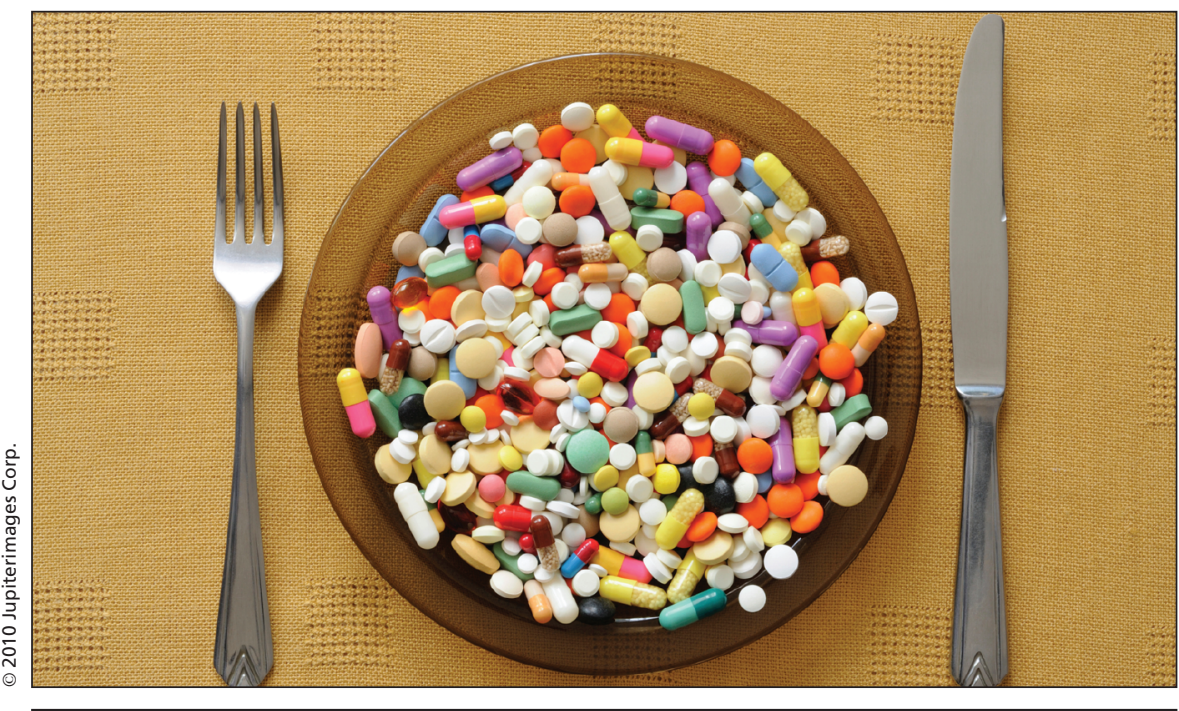

Skeptics of discretionary industry fortification of foods fear that the end result may be nutrient overexposure within the general population and possibly illness, as is the case with trans fats.

the European Commission and Argentina, already allow for discretionary fortification and "there appears to be a certain amount of consumer interest in these types of products," he wrote.

But Valerie Tarasuk, a professor of nutrition at the University of Toronto and a former member of Health Canada's expert advisory committee on dietary reference intakes, scoffs at that logic. "What are we saying there? That we want to take a bad idea and spread it around?" she asks. As for the notion that consumer choice must be expanded, Tarasuk says, "I've read estimates that there as many as 50000 products on our shelves. I don't think we need one more product. I think we maybe need about 40000 fewer. I think that argument, that we need more products is absolutely nonsense."

Tarasuk argues that the goal of food regulation should be to "protect and promote the health of Canadians," not to promote concepts like discretionary fortification.

Little is known about the consequences of fortifying the food supply, she says. While some nutrients have identifiable safe upper limits, many do not. Tarasuk adds that, by definition, discretionary fortification will result in increased nutrient exposure within the general population. If allowed, discretionary fortification may eventually create health risks in the form of chronic, unnecessary overexposure to nutrients.

Many of the risks are not currently understood and there can be unintended consequences from food additives, Tarasuk says, citing the inclusion of trans fats in the food supply as an example. "The potential to displace healthier foods from the diet is very real. It's the essence of the policy and to be doing that in the context of our current problems of overweight and obesity is absolutely irresponsible."

It could take decades of postmarket surveillance to identify the consequences, as was the case with trans fats, she says. It took more than 20 years to amass enough scientific data to conclusively vilify trans fats and even now, three years after the Canadian Trans-Fat Task Force recommended its regulated removal, trans fats are still in the food supply in amounts left to manufacturers' discretion.

Thomas acknowledged in his email that there is a gap in the understanding of 
the potential impact of fortified foods on consumption patterns. It's an "important area that needs to be addressed," he said, adding that educational measures would help consumers make healthy choices.

Tarasuk, though, questions whether education will have any impact when it comes to discretionary fortification.

"People have an understanding of nutrients as good for them," she says. "We can't expect people to know whether or not they need more niacin in their diet, or what their riboflavin status is, or what their pantothenic acid status is. We can't expect an individual going to the store to know those things. Somebody shouldn't need a $\mathrm{PhD}$ to go grocery shopping."

Lynda Corby, registered dietitian and director of public affairs for the Dietitians of Canada, says the problem is compounded by the fact that nutrition facts panels do not indicate whether the source of the nutrients is natural or added. That makes it difficult for consumers to decide whether it is a healthier product, she says.
Corby is also concerned that Health Canada's proposed Codex amendment does not clearly specify which types of foods could be fortified. The Dietitians of Canada, she says, "would certainly want to see some very strict parameters put around the kinds of foods that would be considered."

As proposed, Health Canada's Codex amendment states that "consideration could also be given to the question of whether there is a need for principles regarding the prohibition of voluntary fortification of certain types of foods and if so, which ones."

That basically leaves the door wide open for all foods, but Thomas states that Health Canada is re-evaluating their Codex proposal to determine if some foods should be exempt from discretionary fortification.

Tarasuk wonders if it is even possible to develop a set of conditional criteria for desirable and undesirable foods or nutrients when dietary intakes, choices and needs vary by food consumption patterns across countries.
"The idea that there's a one-size-fits-all for these answers globally I think is crazy," she says.

An array of public health advocacy groups have spoken out against discretionary fortification, including the Dietitians of Canada, the Canadian Diabetes Association, the Heart and Stroke Foundation of Canada, the Canadian Paediatric Society, the Coalition québécoise sur la problématique du poids, the Canadian Public Health Association, the Ontario Public Health Association and the Ontario Society of Nutrition Professionals in Public Health. That prompts Tarasuk to wonder about Health Canada's motivations.

"If there aren't health advocates demanding more niacin in potato chips or more B vitamins in fruit-flavoured water, who's advocating for it?" she asks. "If it isn't health practitioners, it's got to be manufacturers and why would Health Canada then make that a priority?" Yoni Freedhoff MD, Ottawa, Ont.

DOI:10.1503/cmaj.109-3185

\section{United States scrambles for secure, safe isotope supply}

Previously published at www.cmaj.ca

$\mathrm{B}$ uffeted by geopolitics from afar and the needs of patients at home, the United States is moving on two fronts to secure the supply of isotopes vital in medical imaging but dangerous in the wrong hands.

No longer able to depend on the traditional Canadian and Dutch suppliers, Washington is accelerating efforts to jump-start domestic production of the molybdenum- 99 isotope. At the same time, policy-makers want to wean the world off of the weapons-grade uranium used to make isotopes and achieve conversion to low-enriched uranium, a promising but unproven path to solving the global isotope shortage.

This tricky juggling act is incorporated in legislation before the US Congress. It was spurred by the indefinite loss of supplies from Canada's National Research Universal (NRU) reactor in Chalk River, Ontario, and

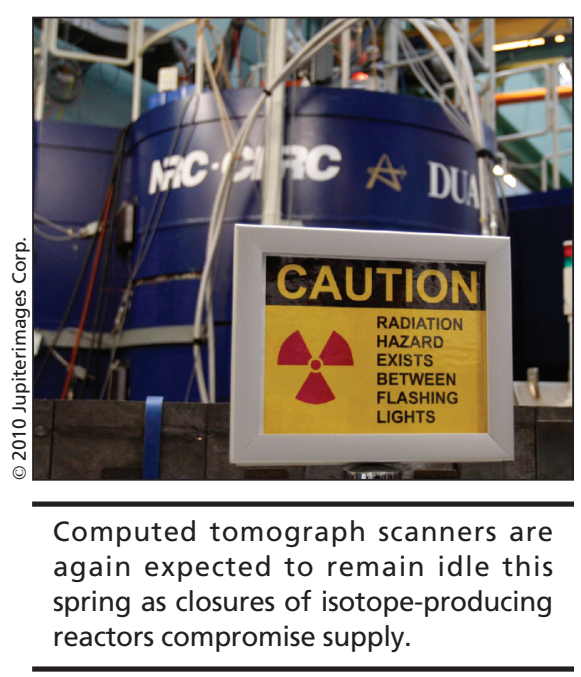

extended interruptions from the other major source, in the Netherlands.

The House of Representatives passed a bill in November 2009, with overwhelming support from both parties, which would release US\$163 million over five years to find means of producing the isotope from lowenriched uranium.

The legislation also would ban the export of highly enriched uranium in seven to 11 years, putting pressure on foreign producers to stop using materials that can be diverted to nuclear weapons development. A similar bill cleared a Senate committee in January, then stalled as a senator sought further study.

This, as supplies have plunged over the past year to $20 \%-30 \%$ of needed levels, leaving caregivers scrambling to keep up in the diagnosis and treatment of cancer, heart disease and other medical conditions. The US found short-term alternatives when the Chalk River reactor was shut down but now the High Flux Reactor in Petter, the Netherlands, is closed for repairs until August.

"It's not a very good situation," says Dr. Michael M. Graham, president of the US Society of Nuclear Medicine. Society 